\title{
Ultrasonographic Comparison of Previous Caesarean Scar Thickness in Second and Third Trimester of Current Pregnancy
}

\author{
Ammara Zahid \\ MSc Medical Ultrasound Technology, Department of Radiological Sciences and medical imaging technology, \\ University of Lahore \\ Dr. Sajid Shaheen Malik \\ MBBS.DMRD MSc Ultrasound, Department of Radiological Sciences and medical imaging technology \\ Dr. Saima Shehzad \\ Senior Gynaecologist, Saima Medical centre \\ Amna Babar \\ Masters in Diagnostic Ultrasound, Lecturer, Department of Allied Health Sciences, Superior College Lahore, \\ University Campus, 17-KM Raiwaind Road, Kot Arain, Lahore, Pakistan \\ Syed Muhammad Yousaf \\ (PhD Diagnostic Ultrasound Scholar (UOL), Master of Philosophy Medical Ultrasound Technology (UOL))
}

\begin{abstract}
Background:

The rate of caesarean section is increasing in the world. With which there is an increase in complications of pregnancy. There is risk of the uterine rupture if there is trial of the normal delivery. The aim of study is to determine and compare previous caesarean scar thickness in second and third trimester of pregnancy.

Objective(s):

To determine previous caesarean scar thickness in second and third trimester of current pregnancy.

Methodology:

An analytical study was conducted in the Saima medical center Shalimar link road Lahore. Sixty-two patients were enrolled in this study with convenient sampling. Toshiba nemio 10 ultrasound machines with convex transducer frequency range 3.5 MHz.patients with placenta previa and twin gestation were excluded from this study. Transabdominal technique was used in this study. Data were collected through data collection sheets and was tabulated and analyzed using statistical package for the social sciences (SPSS)version 24(SPSS, IBM, Armonk, NY, United States of America) Microsoft excel.

Results:

A total of 62 patient were examined in the study. The age incidence of the cases in this study varied between 22 years to 36 years. The mean age of the patients in the study was 27. 2903. The mean gestational age was 27.47. The mean scar thickness at 24-28 weeks was3.3925. parity varied patient to patient.16(25.8\%) females had para 2.23(37.1\%) had para 3 and 16(25.8\%) had para 4.3(4.8\%) females had para 5 and 4(6.5\%) had para 6 . In the current study out of sixty-two patients $13(21 \%)$ were gravida1,24(38.7\%) was gravid 2,17(27.4) were gravid $3,4(6.5 \%)$ gravid 4 and (6.5) gravid. A statistical significance difference found in mean scar thickness at 24-28 weeks of gestation and at 32-36 weeks of gestation-value $=0.000<\alpha=0.05$.

Conclusion(s):

ultrasound is the useful modality for determining scar thickness. The scar thickness of previous c section in the current pregnancy.

Keywords: Analytical study, cesarean scar thickness

DOI: $10.7176 / \mathrm{JHMN} / 93-02$

Publication date:September $30^{\text {th }} 2021$

\section{INTRODUCTION}

Caesarean section is one of the most incessant careful tasks performed in the UK and worldwide. ${ }^{1}$ The CS rate expanded from $12 \%$ to $29 \%$ somewhere in the range of 1990 and 2008 in the United Kingdom and from $21.2 \%$ to $30.1 \%$ in the United States. ${ }^{2,3}$ The expanding CS rate and its related entanglements has invigorated an enthusiasm for the conduct of CS scars and their related potential grimness among wellbeing experts. The rate of uterine rupture in preliminaries of $\mathrm{VBAC}$ has stayed static with a recurrence assessed at somewhere in the range of $0.2 \%$ and $3.8 \% .{ }^{4} \mathrm{Be}$ that as it may, the future execution of the uterus after CS is as yet an underexplored zone of research, quite compelling is the impact of cesarean scar on pregnancy implantation, and the improvement of conventions for early forecast of effective preliminaries of VBAC. In the previous decade, we have seen a fast
\end{abstract}


advancement in imaging, and ultrasound filtering specifically has prospered in the field of obstetrics and gynecology with respect to new improvements in the analysis of polycystic ovaries and different inborn fetal anomalies. The presence of the CS scar utilizing ultrasound might be applicable, yet there is constrained proof to relate the scar appearances with work. ${ }^{5}$, incomplete healing of uterine scar is a frequent complication of CS and may result in the potential entanglements. Uterine scar imperfections are associated with gynecological problems such as spotting, dysmennohrea, and, pelvic discomfort and unfavorable obstetrical results for example ectopic pregnancies, placenta accerta and uterine rupture one of the most disastrous obstetrical crises. ${ }^{6}-{ }^{8}$ Lower uterine segment thickness as measured by ultrasound assessment in third trimester of pregnancy results in uterine scar defect or uterine rupture during trial of vaginal delivery. A fine lower uterine segment increases the risk of uterine scar dehiscence or uterine rupture during normal delivery. ${ }^{9}$ The prevalence reported for the scar dehiscence was near $0.2-4.3 \%$ of all pregnancies related to previous caesarean. ${ }^{10} \mathrm{~A}$ fruitful vaginal birth after cesarean (VBAC) is related with less intricacies than an elective rehash cesarean area. It is better to done elective repeat LSCS than unsuccessful normal delivery. ${ }^{11}$ The benefits of vaginal delivery prevention from abdominal surgery, reduces the chances of postpartum hemorrhage and lessens the time of healing after delivery. It decreases the chances of again c section, cesarean hysterectomy, bowel and bladder damage, require for blood transfusion and irregular placental conditions in future e.g placenta previa and placenta accreta. ${ }^{12}$

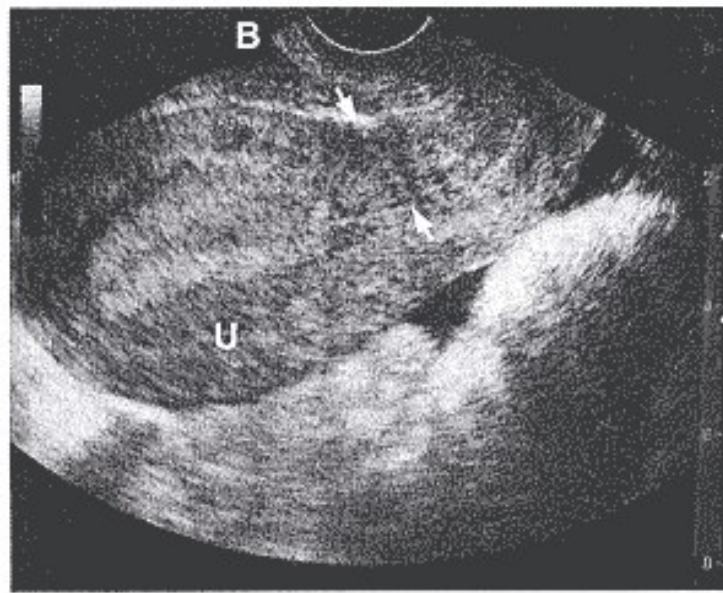

Ultrasound follow-up of the uterine scar at 6 weeks cesarean delivery by transabdominal approach. B, bladder;

$U$, uterus. The scar is between the two arrows.

Figure.1. Ultrasound follow up of the uterine scar 6 weeks cesarean delivery by Trans abdominal approach

Consequences of vaginal birth after c section are uterine rupture which is harmful to life which results in hemorrhage. Several methods are used to study the integrity of scar. The methods include post-operative Eco graphic assessment of uterine injury, interval hysterography and MRI imaging. Ultrasound can be used to examine the reliability of previous caesarean scar. ${ }^{13}$ It can be useful to determine uterine rupture during delivery and identify the lower uterine thickness. The lower uterine segment thickness can be classified into 4 groups. Group 1 shows well-formed uterine segment. Group 2 shows a fine uterine scar with no uterine substances visible in it. Group 3 shows scar dehiscence. Group 4 shows dehisced or rupture scar. Components associated with uterine scar rupture during normal delivery are number of LSCS, inter delivery interval, previous normal delivery, gestational age and birth weight. Enhancements in imaging have encouraged the assessment of CS scars both before and during pregnancy. Ultrasonography has been utilized to assess CS scars in late pregnancy. ${ }^{14}$ Expectation of the scar dehiscence will be helpful in selection of patients. There are different methods to investigate the scar thickness including son hysteroscopy, MRI, hysteroscopy. Different values have been given by authors for the trial of normal delivering ranging from $2.5-3 \mathrm{~mm}$ which value is the best is still a controversy. Ultrasonography (USG) provides a fairly simple and noninvasive method, which has been most widely studied for evaluation of the LUS to assess the critical thickness above which safe vaginal delivery is predictable and safe. It saves the patients from unnecessary surgery and we reduce the number of patients from caesarean section and uterine rupture.

\section{RESULTS:}

According to the table below, total 62 patient were included in this study, the minimum age is 22 and the maximum age is 36 . The mean \pm S.D are $27.2 \pm 3.12$. 


\section{Descriptive Statistics of Age}

\begin{tabular}{rr|r|r|r|r|r|r} 
& \multicolumn{4}{c}{ Descriptive Statistics } & \multicolumn{2}{c}{ Nean } & \multicolumn{2}{c}{$\begin{array}{c}\text { Std. Deviation } \\
\text { N }\end{array}$} & Range & Minimum & Maximum & \multicolumn{2}{c}{ Mean } \\
& Statistic & Statistic & Statistic & Statistic & Statistic & Std. Error & Statistic \\
\hline Age & 62 & 14.00 & 22.00 & 36.00 & 27.2903 & .39590 & 3.11731 \\
\hline
\end{tabular}

\begin{tabular}{|c|c|c|c|c|c|c|c|}
\hline \multicolumn{8}{|c|}{ Descriptive Statistics } \\
\hline & \multirow{2}{*}{$\begin{array}{c}\mathrm{N} \\
\text { Statistic } \\
\end{array}$} & \multirow{2}{*}{$\begin{array}{c}\text { Range } \\
\text { Statistic }\end{array}$} & \multirow{2}{*}{$\begin{array}{l}\text { Minimum } \\
\text { Statistic }\end{array}$} & \multirow{2}{*}{$\begin{array}{l}\text { Maximum } \\
\text { Statistic }\end{array}$} & \multicolumn{2}{|c|}{ Mean } & \multirow{2}{*}{$\begin{array}{c}\text { Std. Deviation } \\
\text { Statistic } \\
\end{array}$} \\
\hline & & & & & Statistic & Std. Error & \\
\hline Gestational age & 62 & 14.00 & 24.00 & 38.00 & 27.4677 & .51149 & 4.02744 \\
\hline
\end{tabular}

The descriptive statistics of gestational age of 62 patients includes minimum and maximum gestational age are 24 and 28 . The mean \pm S.D $27.47 \pm 4.027$ according to the table2.

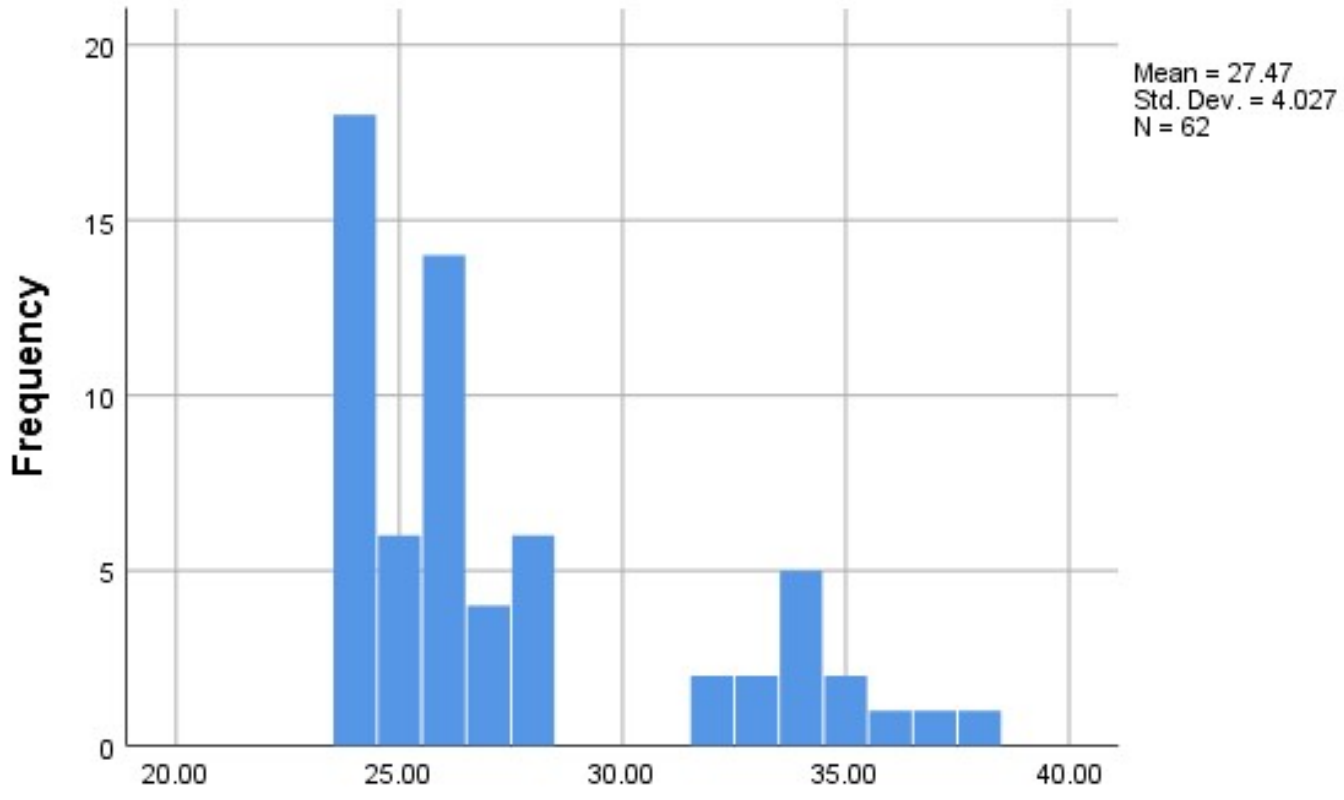

Gestational Age (Weeks)

\begin{tabular}{|c|c|c|c|c|c|}
\hline \multicolumn{6}{|c|}{ Descriptive Statistics } \\
\hline & $\mathrm{N}$ & Minimum & Maximum & Mean & Std. Deviation \\
\hline Scar Thickness 24-28 weeks & 124 & 1.00 & 13.60 & 3.9395 & 2.50923 \\
\hline Valid N (listwise) & 124 & & & & \\
\hline
\end{tabular}

Out of 124 patients, the scar thickness at $24-28$ weeks the minimum value 1 and maximum was 13.60 . The standard deviation came 2.50 .

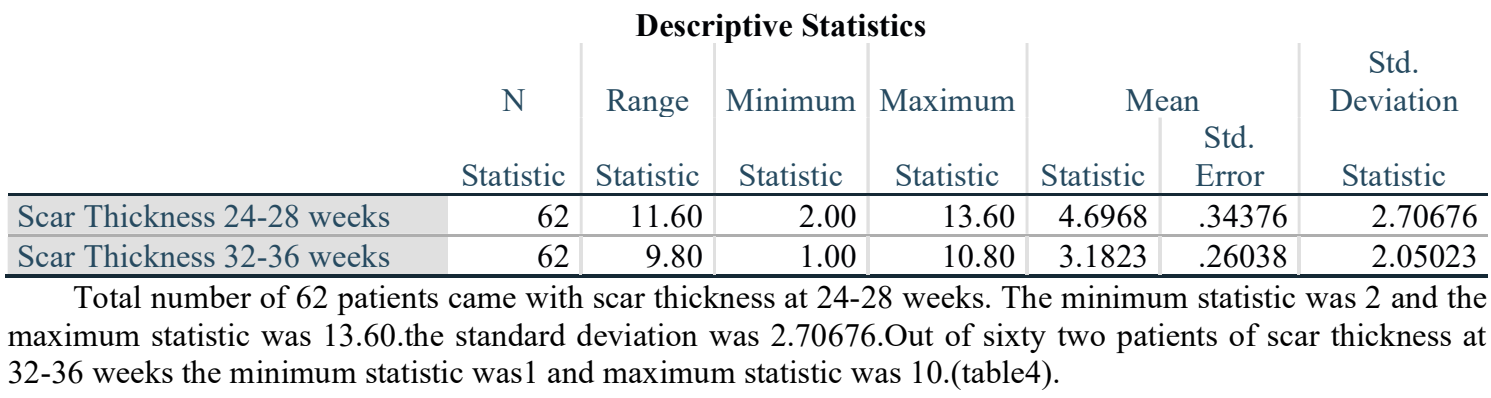




\section{Frequency Table}

\begin{tabular}{l|r|r}
\multicolumn{2}{c}{$\begin{array}{c}\text { Parity } \\
\text { Frequency }\end{array}$} & \multicolumn{1}{c}{ Percent } \\
\hline 2 & 16 & 25.8 \\
\hline 3 & 23 & 37.1 \\
\hline 4 & 16 & 25.8 \\
\hline 5 & 3 & 4.8 \\
\hline 6 & 4 & 6.5 \\
\hline Total & 62 & 100.0 \\
\hline
\end{tabular}

In our current study out sixtytwopatients $16(25.8 \%)$ para 2,23(37.1\%) para3,16(25.8\%) para4,3(4.8\%) para 5 and $4(6.5 \%)$ para6.

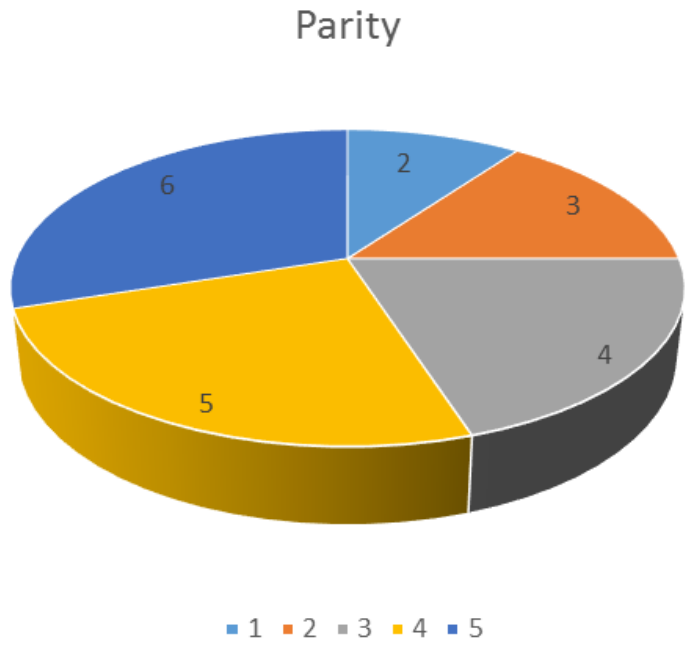

\section{Gravidity}

\begin{tabular}{|c|c|c|}
\hline & Frequency & Percent \\
\hline 1 & 13 & 21.0 \\
\hline 2 & 24 & 38.7 \\
\hline 3 & 17 & 27.4 \\
\hline 4 & 4 & 6.5 \\
\hline 5 & 4 & 6.5 \\
\hline Total & 62 & 100.0 \\
\hline
\end{tabular}

In the current study out of sixty-two patients 13(21\%) were gravida1,24(38.7\%) was gravid 2,17(27.4) were gravid 3,4(6.5\%) gravid 4 and 4(6.5) gravid5. (table6) 


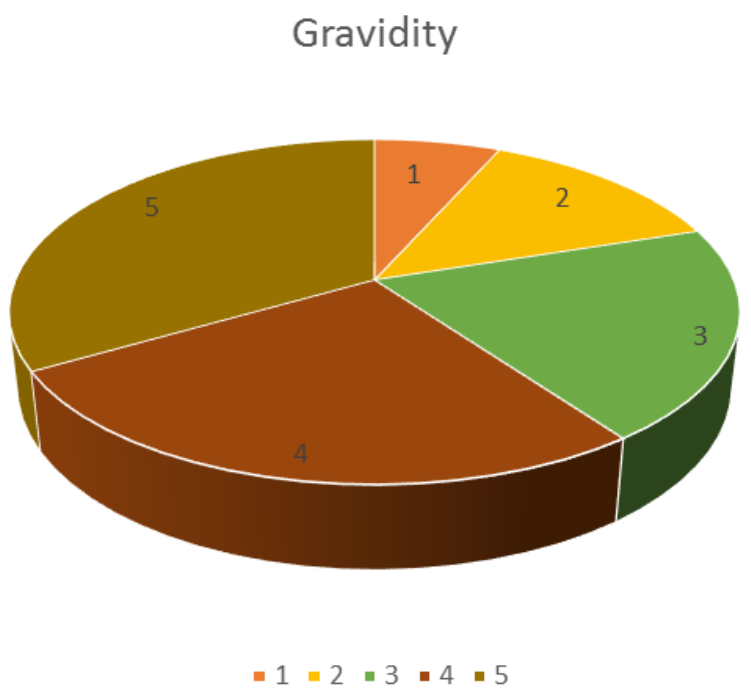

Comparison

Paired Differences

\begin{tabular}{|c|c|c|c|c|c|c|c|c|}
\hline \multicolumn{6}{|c|}{ Paired Differences } & \multirow[b]{3}{*}{$\mathrm{t}$} & \multirow[b]{3}{*}{$\mathrm{df}$} & \multirow{3}{*}{$\begin{array}{l}\text { Sig. (2- } \\
\text { tailed) }\end{array}$} \\
\hline & \multirow[b]{2}{*}{ Mean } & \multirow{2}{*}{$\begin{array}{c}\text { Std. } \\
\text { Deviation }\end{array}$} & \multirow{2}{*}{$\begin{array}{l}\text { Std. Error } \\
\text { Mean }\end{array}$} & \multicolumn{2}{|c|}{$\begin{array}{l}95 \% \text { Confidence } \\
\text { Interval of the } \\
\text { Difference }\end{array}$} & & & \\
\hline & & & & Lower & Upper & & & \\
\hline $\begin{array}{l}\text { Scar Thickness } \\
24-28 \text { weeks } \\
\text { Scar Thickness } \\
32-36 \text { weeks }\end{array}$ & 1.51452 & 1.44720 & .18379 & 1.14700 & 1.88204 & 8.240 & 61 & .000 \\
\hline
\end{tabular}

A statistical significance difference found in mean scar thickness at 24-28 weeks of gestation and at 32-36 weeks of gestation.p-value $=0.000<\alpha=0.05$.

\section{CHAPTER 6}

\section{DISCUSSION}

The main aim of this study was to compare caesarean scar thickness in second and third trimester of pregnancy.c section is one of the common surgery performing all around the world.

The current study evaluated 62 patients between the age group of 22 to 36 years of age. According to the table 1.The mean of age came out to be 27.29.this is well correlated with previous study done by Vikhareva et al in 2009 , showing the mean age of $27.10 \pm 6.01$ years $^{52}$.

In current study 62 patients geataional age is between 24 to 26 weeks with mean of 27.47 which we correlate with the previous study of Jastrow et al. Cheung etal Micheal et which perform this study in 3 trimester between 27 to 40 weeks of gestation $27.91 \pm 2.126$ weeks. ${ }^{53}$

In the current study we found scar thickness at $24-28$ weeks is 3.93 according to the table 3 .which we correlate with the previous study which was performed by the Gotoh et al in which he found no differences in scar thickness at 24 to 26 gestational age ${ }^{54}$.

In this study we found more patients with parity 3 according to table 5.which we correlate with the previous study in which Only one (1.4\%) patient was having parity of more than

5 with a mean parity of $2.01 \pm 0.95$ these findings are by Qureshi ${ }^{55}$.

In our study mostly patients are gravida 2 according to table 6 .we correlate it with the previous study in which mostly paients were gravida 3 and 4 .this study was performed by Fukude $e t a l^{56}$.

In our study we found statical difference in scar thickness at 24 to 28 and 34 to 36 weeks .p-value $=0.000<\alpha=$ 0.05 . According to the table 6 which we correlate with the previous study in which there is association between the scar thickness and intraoperative findings in which value of $\mathrm{p}-0.001$. this study was performed by the Mohammad $^{57}$. 


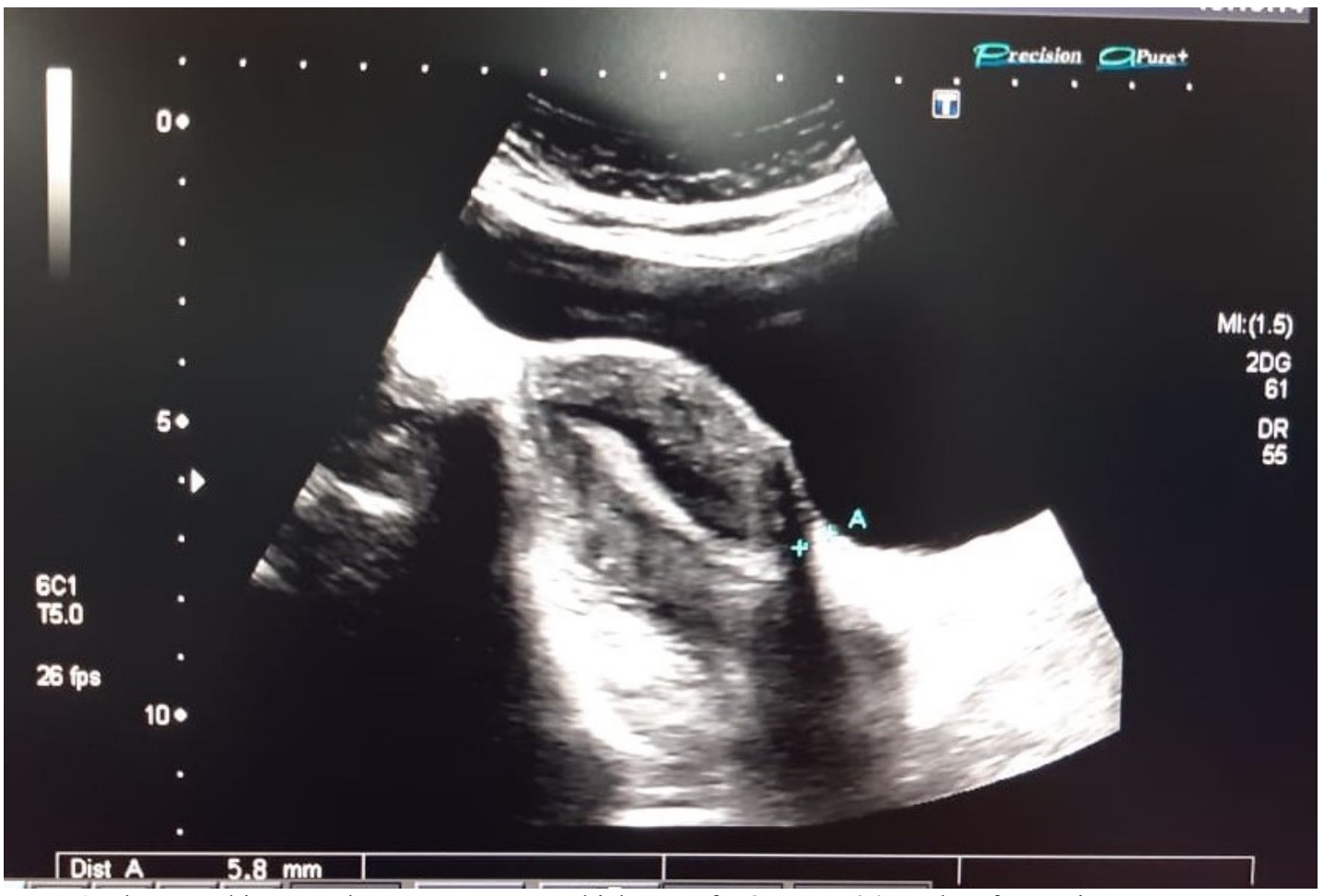

Case 1:Ultrasound images show cesarean scar thickness of $5.8 \mathrm{~mm}$ at 34 weeks of gestation.

\section{REFERENCES}

1. Yazicioglu F, Gökdogan A, Kelekci S, Aygün M, Savan K. Incomplete healing of the uterine incision after caesarean section: is it preventable? European Journal of Obstetrics \& Gynecology and Reproductive Biology. 2006 Jan 1;124(1):32-6.

2. Betrán AP, Merialdi M, Lauer JA, Bing - Shun W, Thomas J, Van Look P, Wagner M. Rates of caesarean section: analysis of global, regional and national estimates. Paediatric and perinatal epidemiology. 2007 Mar;21(2):98-113.

3. Bevan H, Robert G, Bate P, Maher L, Wells J. Using a Design Approach to Assist Large-Scale Organizational Change: "10 High Impact Changes" to Improve the National Health Service in England. The Journal of Applied Behavioral Science. 2007 Mar;43(1):135-52.

4. Ofili - Yebovi D, Ben - Nagi J, Sawyer E, Yazbek J, Lee C, Gonzalez J, Jurkovic D. Deficient lower segment Cesarean section scars: prevalence and risk factors. Ultrasound in Obstetrics and Gynecology: The Official Journal of the International Society of Ultrasound in Obstetrics and Gynecology. 2008 Jan;31(1):72-7.

5. Bij de Vaate AJ, Brölmann HA, Van Der Voet LF, Van Der Slikke JW, Veersema S, Huirne JA. Ultrasound evaluation of the Cesarean scar: relation between a niche and postmenstrual spotting. Ultrasound in Obstetrics \& Gynecology. 2011 Jan;37(1):93-9.

6. Blanchette H. The rising cesarean delivery rate in America: what are the consequences?. Obstetrics \& Gynecology. 2011 Sep 1;118(3):687-90.

7. Lisonkova S, Muraca GM, Potts J, Liauw J, Chan WS, Skoll A, Lim KI. Association between prepregnancy body mass index and severe maternal morbidity. Jama. 2017 Nov 14;318(18):1777-86.

8. Hamilton BE, Hoyert DL, Martin JA, Strobino DM, Guyer B. Annual summary of vital statistics: 2010-2011. Pediatrics. 2013 Mar 1;131(3):548-58.

9. Bujold E, Jastrow N, Simoneau J, Brunet S, Gauthier RJ. Prediction of complete uterine rupture by sonographic evaluation of the lower uterine segment. American journal of obstetrics and gynecology. 2009 Sep 1;201(3):320

10. Sen S, Malik S, Salhan S. Ultrasonographic evaluation of lower uterine segment thickness in patients of previous cesarean section. International Journal of Gynecology \& Obstetrics. 2004 Dec;87(3):215-9.

11. Tazion S, Hafeez M, Manzoor R, Rana T. Ultrasound predictability of lower uterine segment cesarean section scar thickness. J Coll Physicians Surg Pak. 2018 May 1;28(5):361-4.

12. Troyano JM, Clavijo MT, Casas S, Martinez-Wallin I, Marco OY, Zurita A. Cesarea scar hysterotomy. 
Assessment by 3D transvaginal-echography. The Ultrasound Review of Obstetrics and Gynecology. 2004 Sep 1;4(3):208-13.

13. Cheung VY. Sonographic measurement of the lower uterine segment thickness in women with previous caesarean section. Journal of obstetrics and gynaecology Canada. 2005 Jul 1;27(7):674-81.

14. Jastrow N, Chaillet N, Roberge S, Morency AM, Lacasse Y, Bujold E. Sonographic lower uterine segment thickness and risk of uterine scar defect: a systematic review. Journal of Obstetrics and Gynaecology Canada. 2010 Apr 1;32(4):321-7.

15 Tazion S, Hafeez M, Manzoor R, Rana T. Ultrasound predictability of lower uterine segment cesarean section scar thickness. J Coll Physicians Surg Pak. 2018 May 1;28(5):361-4.

16. Maged AM, Gebril AH, Abdelhafez A. 2D and 3D ultrasound assessment of cesarean section scars and its correlation to intraoperative findings. Uterus \& Ovary. 2015;2:1-7.

17. Regnard C, Nosbusch M, Fellemans C, Benali N, Van Rysselberghe M, Barlow P, Rozenberg S. Cesarean section scar evaluation by saline contrast sonohysterography. Ultrasound in Obstetrics and Gynecology: The Official Journal of the International Society of Ultrasound in Obstetrics and Gynecology. 2004 Mar;23(3):289-92.

18. Sen S, Malik S, Salhan S. Ultrasonographic evaluation of lower uterine segment thickness in patients of previous cesarean section. International Journal of Gynecology \& Obstetrics. 2004 Dec;87(3):215-9.

19. . Nargis N, Al-Mahmood AK, Akhter D. Evaluation of uterine scar on repeat second cesarean section in patients with previous cesarean section. Anwer Khan Modern Medical College

20.Jastrow N, Chaillet N, Roberge S, Morency AM, Lacasse Y, Bujold E. Sonographic lower uterine segment thickness and risk of uterine scar defect: a systematic review. Journal of Obstetrics and Gynaecology Canada. 2010 Apr 1;32(4):321-7 Journal. 2012;3(1):16-9.

21. Malik J, Das A, Rai P, Das S. Risk of Scar Dehiscence in Women with Previous Cesarean Section on U1trasonography. MJ Gyne. 2 (1): 009. Citation: Malik J, Das A, Rai P and Das S.(2017). Risk of Scar Dehiscence in Women with Previous Cesarean Section on Ultrasonog-raphy. MJ Gyne. 2017;2(1):009

22. Prabhakar M, Tyagi S. Retrospective study to find predictive factors of scar dehiscence in previous caesarean section to prevent maternal and perinatal morbidity and mortality. International Journal of Reproduction, Contraception, Obstetrics and Gynecology.;8(2):532

23. Thomas A, Rebekah G, Vijayaselvi R, Jose R. Transvaginal ultrasonographic measurement of lower uterine segment in term pregnant patients with previous cesarean section. Open Journal of Obstetrics and Gynecology. 2015;5(11):646.

24. Suzuki S, Sawa R, Yoneyama Y, Asakura H, Araki T. Preoperative diagnosis of dehiscence of the lower uterine segment in patients with a single previous Caesarean section. Australian and New Zealand Journal of Obstetrics and Gynaecology. 2000 Nov;40(4):402-4.

25. Stirnemann JJ, Chalouhi GE, Forner S, Saidji Y, Salomon LJ, Bernard JP, Ville Y. First-trimester uterine scar assessment by transvaginal ultrasound. American journal of obstetrics and gynecology. 2011 Dec 1;205(6):551-e1

26. Jha NN, Maheshwari S, Barala S. Ultrasonographic assessment of strength of previous cesarean scar during pregnancy. International Journal of Reproduction, Contraception, Obstetrics and Gynecology.;7(4):1459.

27. Ganapathi T, Chaudhari HK. Ultrasonographic measurement of uterine lower segment scar thickness in cases of previous one caesarean section and obstetric outcome. International Journal of Reproduction, Contraception, Obstetrics and Gynecology.;7(11):4455.

28. Basic E, Basic-Cetkovic V, Kozaric H, Rama A. Ultrasound evaluation of uterine scar after Cesarean section and next birth. Medical Archives. 2012;66:41.

29. Kumari A, Srivastav R, Sahu S. TRANSVAGINAL ULTRASONIC EVALUATION OF LOWER UTERINE SEGMENT TO PREDICT INTEGRITY OF CAESAREAN SCAR DURING PREGNANCY AND ITS CORRELATION WITH OBSTETRIC OUTCOME. Indian Journal of Obstetrics and Gynaecology. 2015 Jan;2(1):7-10.

30. Azeem A, Ibrahim D, Shazely S. THE PREDICTIVE VALUE OF ULTRASONOGRAPHIC ASSESSMENT OF LOWER SEGMENT SCAR INTEGRITY IN PATIENT WITH PREVIOUS CAESAREAN SECTION NEAR TERM. Zagazig University Medical Journal. 2014 Jul 1;20(4):1-8. 